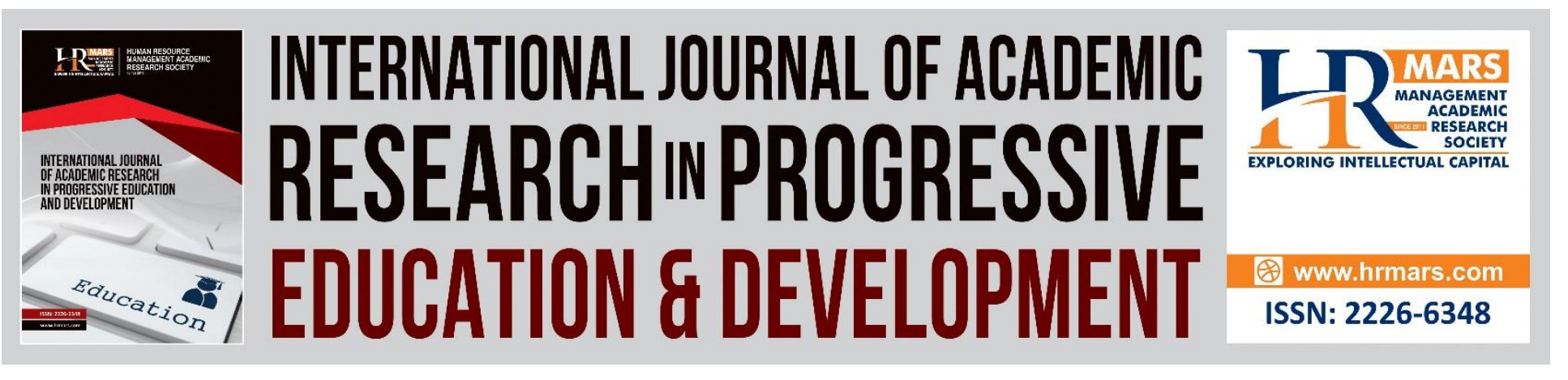

\title{
Voluntary Counselling and Testing Services for Youths with Hearing Impairment: A Case for Masvingo District in Zimbabwe
}

Patricia Mutumburanzou

To Link this Article: http://dx.doi.org/10.6007/IJARPED/v8-i2/5829

DOI: $10.6007 /$ IJARPED/v8-i2/5829

Received: 14 Jan 2019, Revised: 20 Feb 2019, Accepted: 10 March 2019

Published Online: 24 March 2019

In-Text Citation: (Mutumburanzou, 2019)

To Cite this Article: Mutumburanzou, P. (2019). Voluntary Counselling and Testing Services for Youths with Hearing Impairment: A Case for Masvingo District in Zimbabwe. International Journal of Academic Research in Progressive Education and Development, 8(2), 307-317.

Copyright: (c) 2019 The Author(s)

Published by Human Resource Management Academic Research Society (www.hrmars.com)

This article is published under the Creative Commons Attribution (CC BY 4.0) license. Anyone may reproduce, distribute, translate and create derivative works of this article (for both commercial and non-commercial purposes), subject to full attribution to the original publication and authors. The full terms of this license may be seen at: http://creativecommons.org/licences/by/4.0/legalcode

Vol. 8(2) 2019, Pg. 307 - 317

http://hrmars.com/index.php/pages/detail/IJARPED

JOURNAL HOMEPAGE

Full Terms \& Conditions of access and use can be found at http://hrmars.com/index.php/pages/detail/publication-ethics 


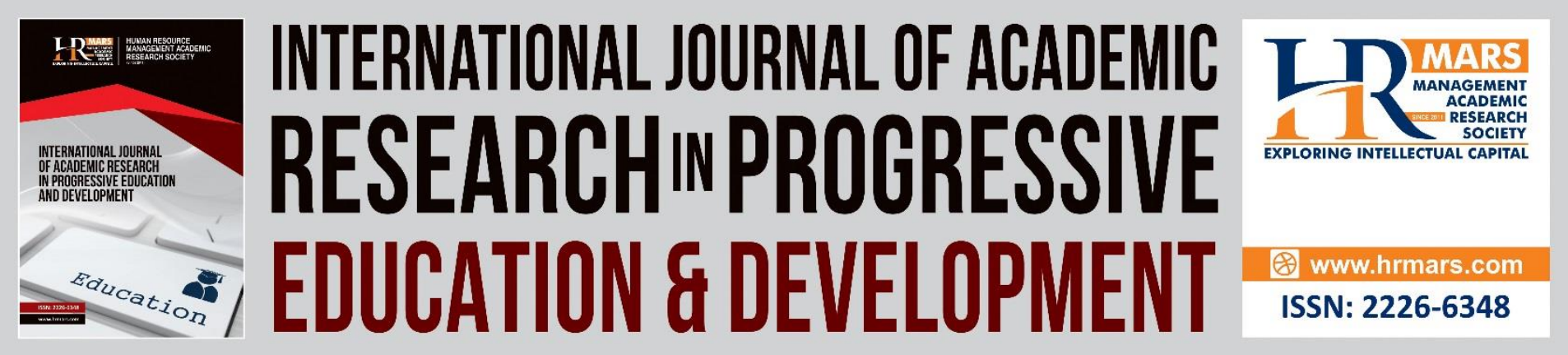

\title{
Voluntary Counselling and Testing Services for Youths with Hearing Impairment: A Case for Masvingo District in Zimbabwe
}

\author{
Patricia Mutumburanzou \\ Lecturer in the Department of Special Needs Education \\ Robert Mugabe School of Education and Culture \\ Great Zimbabwe University, Zimbabwe
}

\begin{abstract}
The study investigates the accessibility of voluntary counselling and testing (VCT) services to youths with hearing impairment in Masvingo District. Hearing influences nearly every aspect of our daily lives, from our ability to access services to the quality of our relationships. Youths with hearing impairment often struggle with significant health disparities due to poor communication competences. The qualitative approach was used and the descriptive survey design was adopted for this study. The sample consisted of 20 youths and 10 counsellors from the VCT service provision departments who were purposively sampled. The youths were interviewed while the VCT counsellors responded to a questionnaire. The results of the study were that many youths with hearing impairment have not been tested for HIV infections because they experience communication barriers and their privacy and confidentiality is not guaranteed. The majority are not able to access the essential services offered to the general populace. It was recommended that access to health care services is a serious issue and that health providers should learn sign language and plan inclusive programmes in order to cater for the needs of young adults with hearing impairment.
\end{abstract}

Keyterms: Hearing Impairment, Counsellor, HIV, AIDS, Voluntary Counselling and Testing, Youth

\section{Introduction}

Access to voluntary counselling and testing (VCT) services should provide youths with hearing impairment an opportunity to gain comprehensive information on HIV and AIDS (National AIDS Control Programme (2005). Youths are particularly vulnerable to HIV due to peer pressure and the development of their sexual and social identities. Through the VCT services, the youths should gain information on HIV and AIDS awareness, prevention, care, support and treatment programmes. The VCT services should provide the youths with hearing impairment the opportunity to fully understand the implications of one's status and further learn about the lifestyles for protecting and 
preventing further spread of HIV and AIDS infection (Adeniyi, Olufemi-Adeniyi, 2014). The services facilitate informed decisions about HIV and AIDS testing. It also enables individuals with hearing impairment to confidentially find out and understand the risk of HIV infection (Owino, 2010). However, it has been generally observed that young people, especially those with hearing impairment face challenges receiving health care services and tend to use the services less than adults do (Adeniyi and Olufemi-Adeniyi, 2014).

\section{Definitions of Terms}

VCT is a process by which an individual undergoes counseling to enable him or her to make informed decisions about being tested for HIV and AIDS. It is a cost effective interaction in high prevalence settings which motivate a positive behaviour change among both HIV positive as well as HIV negative individuals. (Van Houten 2000).

Counselling is a purposeful dialogue between a client and a service provider aimed at enabling an individual to cope with stress and make personal decisions about taking an HIV test, (Fontaine and Fletcher, 2004

Youth is the period between 10 years to 24 years. The terms youth and young people can be used interchangeably (National AIDS Control Programme, 2008).

Hearing Impairment $(\mathbf{H I})$ is a term that refers to anyone with hearing loss that prevents him or her from totally receiving sound through the ear. The loss is significant enough to require special education training and adaptation (Winzer, 1996). HI is a general term used to describe any deviation from normal hearing, whether permanent or fluctuating, and ranging from mild hearing loss to profound deafness. It includes both deaf and hard of hearing.

The term deaf refers to a profound or complete inability to hear. The sense of hearing is not functional for the ordinary purpose of life (Sahu, 2002). The individual experiences total loss of hearing and is disabled to an extent that precludes the understanding of speech through the ear alone, with or without amplification. The individual communicates using sign language.

Hard of hearing refers to an individual with a hearing loss who relies on residual hearing to communicate through speaking and speech-reading (Shemesh, 2010).

\section{Background to the Study}

HIV/AIDS has become one of the major challenges facing mankind since its discovery in 1981 and it has become one of the most destructive epidemics in recorded history (Njoki, 2008). The pandemic disease has no boundaries as its effects are felt by both the non-disabled as well as the disabled (VSO, 2010). The impact of this disease on youths with $\mathrm{HI}$ cannot be ignored. It is one of the major challenges faced by the youths with $\mathrm{HI}$ (Adeniyi and Olufemi-Adeniyi, 2014). Among the youths with $\mathrm{HI}$, Vinga, (2015) notes that the pandemic is seen as a problem that concerns other people and not the hearing impaired themselves. This paradigm shift that attributes HIV and AIDS to the social other may lead to further marginalization of infected individuals (Vinga, 2015). It may also contribute to the complacency and denial of the reality of risk infection. 
The youths with hearing impairment $(\mathrm{HI})$ are exposed to so many disposing factors that can aid the spread of HIV and AIDS. Their problems are further compounded by the inability to hear, speak or make healthy relationships with peers. (Adeniyi and Olufemi-Adeniyi, 2014). They are not able to share or acquire information from the environment mainly due to the communication barrier. Due to their low education, low reading ability and low economic status, the youth with HI have not been able to access the information on the awareness and prevention of HIV/ and AIDS which is disseminated through mass and electronic media such as, television, radio, the internet, newspapers, magazines as well as public advertisements, public talks and seminars (Njoki, 2008). The information via the above systems is generally targeted at the general population who can hear and read a spoken language (Vinga, 2015). The youth with $\mathrm{HI}$ are left out of the messages because they cannot hear and in many instances they are left out in educational campaigns and prevention activities (Njoki, 2008). One wonders whether the youth with $\mathrm{HI}$ in Masvingo District ever bother to access the VCT services in their area in order to make informed decisions about their health statuses.

\section{Literature Review}

Youths with hearing impairment are generally ignorant about AIDS. A World Bank Study which was carried out in 2004 on some 88 students with deafness around the age of 18 in Kenya revealed that $3 / 4$ of them knew very little about AIDS. Furthermore, Opondo in IRIN, (2006) noted that the rate of illiteracy in the region of Kisumu, in Kenya, was very high, which implies that individuals with hearing impairment could not read the information that is distributed mostly by non-governmental organizations on HIV and AIDS. Another study conducted in Maryland in the United States of America shows that people who are deaf are two to ten times as likely as their hearing counterparts to be HIV positive (Monaghan, 2006)

It has been observed that some youths with hearing impairment do not know any sign language at all since $90 \%$ of them are born to hearing parents (Kirk Gallagher and Anastasiow, 2006). Very often, youths with hearing impairment, mainly in remote areas, are generally illiterate in both the spoken and sign languages because they never got the opportunity to go to school, and learn it (IRIN, 2006). It follows that illiteracy and distance remain big problems for individuals with hearing impairment to access essential health services. Moreover, organizations and health centers do not have the resources to travel so widely. In Nigeria it was reported that nearly 1 deaf in 10 is living with HIV and that the rate of mortality among the this population is increasing daily because of the effects of the disease (Adeniyi and Olufemi-Adeniyi, 2014).

The National AIDS Control Programme (NACP), (2008) confirms that young people with HI experience many barriers when they try to access health services. These young people often turn to their peers or the social media for information. (National Aids Control Programme, (2008) further notes that the mass media tends to promote sexuality and safety and as a consequence, the youths with $\mathrm{HI}$ often lack the information they need to make safe and healthy decisions.

Vinga, (2015) reports the sentiments expressed by some youths with $\mathrm{HI}$ at a workshop for peer educators in Zimbabwe. According to Vinga, (2015) in the Sunday Mail dated 29 November, the 
first participant with hearing impairment at the peer educator's workshop says, "you have just said that using condoms will prevent HIV transmission, but I am failing to understand how I will be protected since the condom does not cover the whole body?" the other participant with HI asked, "But even if I go for counselling and testing, how would I be assisted by the officers who cannot communicate in sign language, even the nurses and doctors cannot explain to me what HIV does to the immune system." Before the facilitator responded another youth with hearing impairment presented yet another concern saying, "When I got tested, the counsellor signed that I am negative, but I was so worried because in the sign language diction, negative implies a situation which is not good."

The concerns raised by the youths with $\mathrm{HI}$ at the peer educator's workshop clearly shows that they lack accurate information and knowledge on HIV and AIDS issues. This may be attributed to the fact that talking about sexuality in the African context is taboo. Many adults, including parents are hesitant or not prepared to talk to youths about HIV and AIDS issues (National AIDS Control Programme, 2008). Studies show that youths with $\mathrm{HI}$ are frequently unaware or miss-informed about HIV and AIDS and how it is transmitted and prevented (Vinga, 2015). This state of knowledge constitute a serious danger to the fight against the pandemic. Individuals must get tested and have adequate knowledge about their statuses. (Adeniyi and Olufemi-Adeniyi, 2014). Therefore, most of the youths with $\mathrm{HI}$ fail to acquire information on HIV and AIDS and they usually encounter inadequate school based instruction as well as miss-information from family members and peers.

According to Vinga (2015) the former Miss Deaf Zimbabwe expresses that there is need to adopt a holistic approach in dealing with the above issues through a grassroot mechanism. Sexual and HIV and AIDS education programmes should be introduced in all school based instruction for the hearing impaired be it in the mainstream or residential schools (Adeniyi and Olufemi-Adeniyi, 2014). Voluntary Services Overseas (VSO) (2010) advocates for participatory strategies which enable the youths with $\mathrm{HI}$ to share ideas so that they see the need to go for VCT. This enables them to make informed decisions in relation to living positively or negatively. It is one sure way of helping adolescents with hearing impairment to achieve the right sexual and healthy behaviours. The peer educators participatory approach have proven to be an effective strategy in global HIV/AIDS prevention (Adeniyi and Olufemi-Adeniyi, 2014). However, it has been generally observed with great concern that many awareness and prevention campaigns have been done for the hearing population. The youths with HI fail to access the much needed information.

Nyangairi, of the Deaf Zimbabwe Trust in Vinga (2015) expresses that sign language is the mother tongue for the deaf, which implies that the majority of the people who are deaf may not be able to speak, read and write. This makes it difficult for the deaf to read any materials that convey HIV and AIDS information.

Various strategies can be used to disseminate information to youths with hearing impairment so that they appreciate the need to go for voluntary counseling and testing (Adeniyi, Olufemi-Adeniyi, 2014). Deaf friendly educational tools with pictorial illustrations such as cartoons portraying HIV and AIDS messages, posters, flyers, policies, newsletters banners can be displayed. 


\section{Statement of the Problem}

Despite the country being renowned for implementing some of the best HIV and AIDS intervention, programmes, youths with hearing impairment have limited access to HIV and AIDS information and health services (Vinga, 2015). In many communities, including Masvingo district the programmes focused towards addressing the sexuality issues of young adults rarely included individuals with hearing impairment. There is very little information showing the impact of the numerous campaigns and voluntary counselling and testing service provisions to individuals with hearing impairment in the country. Zimbabwe has very few reports on these issues yet the youths with hearing impairment must enjoy their rights to health and information. The question is, What then becomes of youths with hearing impairment who are generally seen on the streets and road sides selling their wares? Are they benefiting from the voluntary counselling and testing services in Masvingo District, considering the impact of the impairment which is silent and invisible, and that it is one of the least recognised and most misunderstood ailment that can be acquired at any age (Smith, 2001). Interpersonal communication is definitely affected.

\section{Methodology}

The descriptive survey design was adopted for this study. The 10 counsellors were purposively sampled from VCT centres including hospitals and clinics in Masvingo District. Snowball sampling was employed to select the 20 youths with hearing impairment. Questionnaires were administered to the counsellors while interviews were conducted among the youths with hearing impairment. The views of the respondents were arranged in themes and content was presented and analysed (Tesch, 1990).

\section{Results}

\section{Findings from the youths' sample HIV and AIDS}

Most of the youths have heard about HIV and AIDS as well as the voluntary counselling and testing services. However, even when the knowledge of HIV and AIDS is high among youths with hearing impairment, this does not always translate into the use of voluntary counselling and testing services. A good number indicated that they heard about HIV and AIDS at school. Implying that the teachers were making frantic efforts to teach Guidance and Counselling, a subject on the primary school syllabus which deals with HIV and AIDS issues. Some youths heard about HIV and AIDS from their friends while others were informed by their mothers or nurses. A good number of the youths expressed ignorance about the pandemic disease. They said nobody had told them about HIV and AIDS. One respondent indicated that he got the information from written messages. This implies that the respondent might have been in the mild category or may have post-lingual deafness which enabled him or her to decipher short messages. It follow that respondents did not have details pertaining to the problem.

\section{Being Tested}

Half of the respondents had visited the VCT centre. When probed further they indicated that they went to the hospitals housing the VCT centres, for treatment when they were sick. Others went 
because they were pregnant and had to attend the antenatal clinics. Respondents expressed that it was not easy communicating with the nursing counsellors in the hospitals.

The other half of the respondents did not know about VCT services. A good fraction cited that they never went to school so they were ignorant of the facts. Very few had been tested and a large number had not been tested. Those who were expecting were tested, not because they volunteered, but due to their conditions. They further indicated that they were not given the results for their HIV status maybe because the exercise was not voluntary. A rape victim who got pregnant was encouraged to go for testing by her mother.

\section{Knowledge of HIV status}

$12(60 \%)$ of the respondents did not know their status implying that they could be exposed to the risk of living with HIV and AIDS. The few who knew their status were ignorant of the implications of knowing one's status. VCT allows young adults to know their own status and to evaluate their behaviour as well as its consequences (UNICEF, 2012). One respondent cited that the counsellors were not able to communicate in sign language hence failed to provide the much needed counselling. In some cases health personnel relied on written pieces of paper which the youths with HIV found very difficult to read and understand. Most of the respondents knew there was no cure for HIV and AIDS.

When asked if they attended HIV and AIDS VCT outreach programmes most of they said they did not. Only $3(15 \%)$ attended the programmess which were mainly targeting the able bodied youths (Adeniyi, Olufemi - Adeniyi, 2014). Youth with HI were not planned for hence they missed out on very important information. Almost all the respondents expressed that they did not benefit from the VCT services in their localities. This could be because of the language barrier. Moreover there are no sign language vocabulary names for some of the technical terms used in counselling. Counsellors were not able to converse in sign language. They needed the assistance of an interpreter who compromised their right to privacy.

When asked where they would go for treatment, almost all respondents indicated that they sought treatment at the hospital or clinic. In some cases the respondents stated that their families would provide counselling in time of need. However one respondent said, "nobody told me about my status at the hospital because they were not able to sign". Youths with $\mathrm{HI}$ need someone to interpret for them always. This is the unfortunate scene most people with disabilities have to face. Youth with hearing impairment are compelled to share their HIV status with a third party because the counsellors in the health institutions are not able to communicate in sign language (Motlhoka, 2014). This clearly indicates that most of the youth with $\mathrm{HI}$ are not enjoying their right to privacy, education and health. The deaf find it very difficult to read and comprehend the counsellor's notes on pieces of paper.

\section{Findings from VCT Service Providers Language Issues}

The VCT centre staff reported that they sometimes see youths with hearing impairment at some of their centres but they failed to communicate with them since most of them use sign language. The staff were not able to interpret or converse in sign language. They did not have the sign language vocabulary to explain the HIV and AIDS issues to youths with HI. Moreover there are no 
INTERNATIONAL JOURNAL OF ACADEMIC RESEARCH IN PROGRESSIVE EDUCATION AND

DEVELOPMENT

Vol. 8, No. 2, 2019, E-ISSN: 2226-6348 @ 2019 HRMARS

signs for most of the clinical terms. Communication between the staff and the youths with $\mathrm{HI}$ is a major barrier. They cannot share sensitive information on HIV and AIDS with the youths.

\section{Programmes}

The counsellors clearly articulated that there are no awareness and prevention programs specifically for youths with hearing impairment. The programme facilitators are not able to use sign language. They experience a communication barrier. They do not engage interpreters. However one member of staff said "Sometimes clients bring their relatives to interpret." And this compromises the youths' right to confidentiality and privacy. As a result the youths with $\mathrm{HI}$ do not attend the outreach programmes in their communities. Their needs are not catered for yet they have a right to health services as well as knowing their HIV status.

The members of staff in the VCT centre reported that youths with $\mathrm{HI}$ are not benefiting from the counselling services. They do not come for testing hence most of them do not know their status. If at all they come, the counsellors find it very difficult to explain the results to the youths with $\mathrm{HI}$. However, some members of staff reported that they have names of youths with $\mathrm{HI}$ on antiretroviral drugs in their centre's records, implying that those who are sick find their way into the centre maybe with the assistance of relatives or friends. One wonders whether they understand why they are taking the medication.

The youths indicated that they always receive counselling from their families. It clearly shows that the youths do not benefit from professional services because of the communication problem.

\section{Discussion}

It emerged from the findings of the study that youth with hearing impairment have very poor access to HIV and AIDS information. HIV and AIDS information is disseminated through mass and electronic media which the youth with hearing impairment can neither read nor hear. Musiiwa (2014) is in support when he says that young people with HI have no access to adequate HIV and AIDS information.

The youths lamented failure to acquire knowledge because of the gap created by their inability to hear and comprehend and the counsellors' inability to communicate in sign language. The HIV and AIDS awareness and prevention campaigns conducted throughout the district have largely overlooked the individuals with $\mathrm{HI}$ among which ignorance about the disease remains high (IRIN, 2006). Youths with $\mathrm{HI}$ get scanty information from friends, family and some lessons conducted at school.

Youths with $\mathrm{HI}$ do not enjoy the privilege to volunteer to be tested for HIV. They visit the hospital for treatment when they are sick or pregnant. They get tested for HIV and AIDs but they usually do not get the results for their status. This is in agreement with Boff's findings (2015) where he reports that deaf people can be at a disadvantage in making full use of health services in London. The deaf individuals in London are more likely to suffer ill health than the rest of the population because they encounter barriers accessing health services like VCT that should be available to all.

Most of the young adults with $\mathrm{HI}$ are not aware of their status. Almost all the members of VCT staff at the centre unanimously echoed the sentiments that they were not able to communicate in sign language. Lack of sign language proficiency by the health personnel is a serious obstacle for youths with HI to access VCT services (Adeniyi, Olufemi-Adeniyi, 2014). The youth with HI find themselves 
in a predicament because the counsellors cannot communicate in sign language. The youths conceded that the counsellors in the VCT centre would write messages on pieces of paper expecting the youths with $\mathrm{HI}$ to read and understand them.

Several youths affirmed that they have to bring along a friend or a relative to help interpret the results all because of the communication problem (VSO 2010). This definitely violates their rights to health and information and as a result they suffer inadequate treatment. Furthermore, interpreters cannot be relied on in Zimbabwe especially when sign language differs from place to place.

The VCT centres do not have any specific structures or programmes for youths with hearing impairment (Motlhoka 2014). They did not attend the awareness and prevention campaigns because they were mainly targeting the hearing people. Youths with $\mathrm{HI}$ are not planned for hence they miss out on very important information. Most of the youth with $\mathrm{HI}$ do not benefit from professional counsellors but when need arises they get counselled by family members especially the mothers. Those youths who never went to school expressed ignorance when it came to receiving services from VCT centres.

There should be an extensive sign language training programme for personnel in the HIV and AIDS service organization because service providers lack the knowledge to deal with the youths with $\mathrm{HI}$. They usually fail to explain results for the young adults with $\mathrm{HI}$.

\section{Conclusion}

All efforts should be made to ensure that voluntary counselling and testing service centres are userfriendly. Youths with hearing impairment should be included in programmes involving health and life- threatening issues. Communication needs for young adults with hearing impairment should be addressed so that they are brought on board in relation to HIV and AIDS awareness, prevention counselling and testing. It is of paramount importance to address the literacy level of youths with hearing impairment to make HIV and AIDS awareness and VCT utilization a reality. This should address the knowledge gap and sensitize youths on the counselling care and treatment services available at VCT centres. All stakeholders must learn sign language while the youths with hearing impairment should strive to learn the written language to be able to read messages.

\section{Recommendations}

In view of the above discussion the study recommends that:

- Youth with HI be provided with accurate information about sexuality, HIV and AIDS.

- Youth with HI be encouraged to go for HIV and AIDS counselling and testing to ascertain their status.

- Outreach programmes should be inclusive

- Counsellors and all health service providers to learn sign language so as to be able to attend and deliver information to youths with HI in VCT centres.

- Deaf friendly HIV and AIDS counselling service centres to be established in schools and communities.

- Deaf counsellors to be trained so as to be able to manage the deaf friendly HIV and AIDS counselling service centres. 
INTERNATIONAL JOURNAL OF ACADEMIC RESEARCH IN PROGRESSIVE EDUCATION AND DEVELOPMENT

Vol. 8, No. 2, 2019, E-ISSN: $2226-6348$ @ 2019 HRMARS

- Educational tools and techniques must be tailor- made in sign language e.g videos, role plays and so on.

- Associations and parents to lobby and advocate for the rights of youths with HI for example on issues of privacy and confidentiality.

However, in Kenya, the Kisumu VCT centre caters for those with HI. The counsellors providing services also have hearing loss. There is need to upgrade the individuals with $\mathrm{HI}$ to become counsellors as well as teachers of sign language. The study suggests that further research should be done to determine the HIV prevalence among the deaf.

\section{References}

Boff, A. (2015). Access to Health Services for Deaf People. London: London Assembly Health Commitee.

Chakuchichi, D., Chitura, M. \& Gandari, E. (2011). Mitigating the Impact of HIV and AIDS on People with Disabilities through Equitable Information Dissermination. Harare:Zimbabwe Open University. (Online) Available at: www.lis.zou.ac.zw

Fontaine, K. L. \& Fletcher, J. S. (2004). Essentials of Mental Health Nursing. New York: Addison Wesley.

IRIN, (2006). Kisumu VCT Centre Speaking to the Hearing Impaired. IRIN News 13 July 2006. (Online)Available at: www.irinnews.org/news/2006/07/13

Joint United Nations Programme on HIV/AIDS, (2001). The Impact of VCT: A Global Review of the Benefits and Challenges. Geneva: Switzerland Joint United Nations Programme HIV/AIDS: S.n.

Moddley, S. (2011). A Process Evaluation of the Implementation of the HIV/ AIDS Counselling and Testing (HCT) Programme for Employees at a Selected Public Hospital in Kwazulu - Natal (Doctoral dissertation: University of Kwazulu-Natal.. s.I.:s.n.

Monaghan, L. (2006). HIV Infection Statistics for Hearing and Deaf Populations.. In: Analysis and policy suggestions. Deaf Worlds. s.l.:Spring 2006,Vol. 22(1).

Musiiwa, M. (2018). HIV/AIDS Intervention for the Deaf Still a Challenge. Sunday News Online, Sunday June 17, 2018, Zimbabwe. Available at: www.sundaynews.co.zw/hivaidsintervention/for-deaf-still-a-challenge

Mwangi, M. F. (2011). Factors Influencing the Implementation of Provider Initiated Testing and Counselling Services at the Provincial General Hospital Nyeri, Central Province, Kenya. Master of Arts dissertation. Nairobi: University of Nairobi.

National Aids Control Programme (2008). HIV and AIDS Voluntary Counselling and Testing: Module 4: Counselling for Specific Target Groups and Situations. Ministry of Health and Social Welfare: The United Republic of Tanzania. PDF TO GO-vct-05-04-02 pdf

Njoki, K. R. (2008). Dynamics in Utilization of Voluntary Counselling and Testing Services by Persons with Hearing Impairment in Nairobi Kenya. s.I.:s.n.

Owino, O. P. (2010). The Impact of Voluntary HIV/AIDS Counselling and Testing on the Knowledge, Attitudes and Sexual Behaviour of the Deaf in Nairobi Province, Kenya. Nairobi: Daystar University. (Level: M. Sc. Thesis)

Sahu, B. K. (2002). Educating Exceptional Children 
INTERNATIONAL JOURNAL OF ACADEMIC RESEARCH IN PROGRESSIVE EDUCATION AND DEVELOPMENT

Vol. 8, No. 2, 2019, E-ISSN: $2226-6348$ @ 2019 HRMARS

Shemesh, R. (2010). Hearing Impairment: Definitions, Assessment and Management. IN Stone, J. H. and Blouin, M. (Eds.). International Encyclopedia of Rehabilitation. Available on-line http://cirrie.bufallo.ed/encyclopedia/en/article/272

Smith, D. D. (2004). Introduction to Special Needs. Making a difference. Columbus: Merrill.

Tesch, R. (1990). Qualitative Research: Analysis Types and Software. Volume 337. London: Routledge Falmer.

UNAIDS, (2004). WHO Policy Statement on HIV Testing. Geneva Switzerland Joint United Nations Programme on HIV/AIDS. s.I.:s.n.

UNAIDS, (2009). Disability and HIV Policy Brief. s.I.:s.n

UNICEF, (2012). Voluntary Counselling and Testing for HIV/ AIDS. Online. Available at: www.unicef.org/life-skills/index_8017.html

Houten, V. H. (Ed). (2000). HIV/AIDS Voluntary Counselling and Testing: Review of Policies, Programmes and Guidelines in East, Central and Southern Africa. Arusha: Commonwealth Regional Health Community Secretariat.

Vinga, A., (2015). HIV Policy Remains Deaf to Sign Language. The Sunday Mail Nov 29, 2015 Zimbabwe. Online. Available at: www.sundaymail.co.zw/hiv-policy-remains-deaf-tosignlanguage

Voluntary Services Overseas, (2010). A Handbook on Best Practices Regarding HIV and AIDS for People with Disabilities: Services, Policy Advocacy Programming, s.I.: VSO. 2010 bestpractices-inclusion-hivaids-1.pdf.

WHO, n.d. Disability and HIV Policy Brief Onwww.who.int/disabilities/jc1632-policy 02-08-18. Online.

World Bank Study, (2004). In IRIN, (2006) Kisumu Voluntary Counselling and Testing Centre Speaking to the Hearing Impaired. Available at: www.irinnews.org/news/2006/07/13

Winzer, M. (1996). Children with Exceptionalities in Canadian Classrooms. Scarborough: Prentice Hall.https://www.ajol.info/index.php/194355

01-08-18 